\title{
FARKLI ISI EŞANJÖRLERİNE SAHİP KOMBİ CİHAZLARININ PERFORMANSLARININ DENEYSEL OLARAK KARŞILAŞTIRILMASI
}

\author{
Mehmet Fevzi KÖSEOĞLU*, Şenol BAŞKAYA ** ${ }^{* *}$ Tamer ÇALIŞIR ** \\ "Pamukkale Üniversitesi Müh. Fak. Makine Müh. Bölümü 20070 Kınıklı/DENiZLİ \\ ${ }^{* *}$ Gazi Üniversitesi Müh. Fak. Makina Müh. Bölümü 06570 Maltepe/ANKARA \\ mfkoseoglu@pau.edu.tr, baskaya@gazi.edu.tr, tamercalisir@gazi.edu.tr
}

(Geliş/Received: 23.12.2013; Kabul/Accepted: 25.12.2014)

\begin{abstract}
ÖZET
$\mathrm{Bu}$ çalışmada, üç farklı model kombi cihazının özellikleri ve 1sı eşanjör performansları deneysel olarak incelenmiştir. Test edilen kombilerin teknik özellikleri birbirlerine çok yakın ve performans değerleri açısından hepsi yaklaşık aynı güçtedirler. Cihazlar arasındaki en önemli fark 1 sı eşanjör tasarımlarıdır. Testleri gerçekleştirilen kombilerin ilki (K1) bileşik 1s1 eşanjörü, ikincisi (K2) düz 1s1 eşanjörü ve üçüncüsü (K3) çift 1s1 eşanjörü ihtiva etmektedirler. Bu çalışmada öncelikle amaç tüm 1sı hücrelerinin performansının belirlenmesi ve K1 bileşik ısı eşanjörünün üstünlüklerini ve avantajlarını tespit etmektir. Tüm kombiler ısıtma devresinin rejime gelmesi sırasında, 1sıtma devresinin rejimde olması ve devre dışında olması durumlarında kullanım suyunun rejime gelmesi sırasında, benzer şekilde kullanım suyunun devrede olması durumunda isıtma suyunun rejime gelmesi ve son olarak değişik debilerde kullanım suyunun performansı incelenmiştir. Performans belirlemeye yönelik olarak yapılan farklı ve parametrik deneyler sonucunda, bileşik 1sı eşanjörlü kombi cihazının (K1) diğer test edilen kombi cihazlarından 1sı enerjisi transfer özellikleri bakımından üstünlükleri ve avantajları olduğu tespit edilmiştir.
\end{abstract}

Anahtar Kelimeler: Isı eşanjörü, kombi, 1sıl performans

\section{EXPERIMENTAL PERFORMANCE EVALUATION OF COMBI-HEATERS WITH DIFFERENT HEAT EXCHANGER UNITS}

\begin{abstract}
In this study, characteristics of three different combi-heaters and heat exchangers were experimentally investigated. All combi-heaters tested have similar technical specifications and have almost the same heat load. Main difference among the combi-heaters is the type of heat exchanger used. Tests were performed for combi heaters containing a combined heat exchanger (K1), a flat plate heat exchanger (K2), double heat exchanger (K3). The objective of this study is to determine the performance of all combi heaters and to determine the benefits and advantages of K1. Performance of all combi heaters were investigated for the heating cycle, domestic water cycle with and without the heating cycle in use, and similarly heating cycle with domestic water in use and finally for different mass flow rates. According to the results of different and parametric experiments for performance evaluation, for the combi heater with combined heat exchanger (K1), advantages in heat transfer characteristics have been detected compared to the other two combi-heaters tested.
\end{abstract}

Keywords: Heat exchanger, combi heater, thermal performance

\section{GIRIŞ (INTRODUCTION)}

Isı eşanjörleri birçok endüstriyel uygulamada kullanılmaktadır ve çok farklı türleri mevcuttur. Isı eşanjörleri tasarımı ve farklı uygulama alanlarına yönelik ayrıntılı bilgiler içeren birçok kaynak mevcuttur [1-3]. "Kombi” cihazı, TS EN 625'de [4] merkezi ısıtma ve sıcak kullanım suyu üretimi için tasarımlanmış kazan veya bileşik ısıtma cihazı yani kombine kazan (kombi) olarak tanımlanmıştır. Kombi 
cihazının en önemli parçalarından birisi 1s1 eşanjörüdür. Kombilerde 1sı eşanjörünün görevi, yakıtın yanması sonucunda ortaya çıkan ısının merkezi ısıtmada kullanılacak olan iş akışkanına ve sıcak kullanım suyuna aktarılmasını sağlamaktır. Kombilerde bu amaca yönelik iki alternatif uygulama mevcuttur. Bunlardan birincisi bileşik ısı eşanjörüdür. Bileşik ısı eşanjöründe hem isıtma devresine hem de kullanım suyuna isı tek bir eşanjörden aktarılmaktadır. İkinci seçenek ise çift eşanjörlü sistemlerdir. $\mathrm{Bu}$ sistemlerde ana eşanjör 1sitma devresine 1sı aktarırken, kullanım suyunu ısıtmak için ikinci bir eşanjör (genellikle plakalı eşanjör) kullanılır. Bileşik ısı eşanjörlü sistemlerde sadece bir 1S1 eşanjörü kullanılır. Bu eşanjör iç içe geçmiş serpantinler vasitasiyla hem isitma suyuna hem de kullanım suyuna yanma sonucunda açığa çıkan 1sıyı aktarabilmektedir. Eşanjör, yanma odasının üst bölümünde konumlandırılır ve böylece doğrudan yanma gazlariyla ve alevle temas halindedir. Isitma suyu ve kullanım suyu bir bakıma 1sıl olarak sürekli temas halindedirler. Çift eşanjörlü sistemlerde ise bir ana eşanjör ve bir de ikincil eşanjör bulunur. Ana eşanjör yine yanma odasındadır ve tüm 1sı enerjisi öncelikle bu eşanjöre aktarılır. Isıtma devresindeki su, bu ana eşanjör ile 1sıtılır. Kullanım suyu ise genellikle plakalı eşanjör olarak imal edilen ikincil eşanjörle 1sıtılır. Plakalı eşanjörün bir tarafından 1sıtılması gereken kullanım suyu, diğer taraftan ise bir üç yollu vana (saptırıcı valf) ile ana eşanjörden aktarılan sıcak su geçer. Diğer bir deyişle çift eşanjörlü sistemlerde sıcak kullanım suyu elde etmek için önce 1sıtma devresindeki su ana eşanjörde 1sitılır ve daha sonra bu sıcak su plakalı eşanjörde ısısını kullanım suyuna aktarır. Plakalı eşanjör, yanma odası dışında bir yere monte edilir. Böylelikle çift eşanjörlü sistemlerde ısıtma devresi suyu ile kullanım suyu birbirinden bağımsız yerlerdedir. $\mathrm{Bu}$ çalışmanın amacı söz konusu eşanjörlerin performanslarını parametrik bir çalışma gerçekleştirerek deneysel olarak incelemek, avantaj ve dezavantajlarını tespit etmektir. Ayrıca tüm
1S1 hücrelerinin performansının belirlenmesi ve K1 1S1 hücresinin üstünlüklerinin ve avantajlarının gözlemlenmesi amaçlanmıştır.

Bu çalışmada merkezi isıtma ve sıcak kullanım suyu üretiminde hem ülkemizde hem de dünyada oldukça yaygın olarak kullanılan kombi cihazlarının daha yüksek sıcaklıklar elde edilerek daha yüksek isıtma güçleri ile çalıştırılması ve böylece kombilerin yakıt tüketiminin ve bununla birlikte emisyonların azaltılması yönünde geliştirmeler hedeflenmiştir. Bu kapsamda her üç kombi cihazı farklı çalışma şartlarında çalıştırılarak parametrik deneysel çalışmalar gerçekleştirilmiştir. Aynı zamanda K1 bileşik kombi cihazının üstünlükleri de tespit edilmeye çalışılmıştır.

\section{DENEY DÜZENEĞİ (EXPERIMENTAL SETUP)}

Merkezi 1sıtma ve sıcak kullanım suyu üretiminde oldukça yaygın olarak kullanılan kombi cihazlarının daha yüksek sıcaklıklar elde edilerek daha yüksek 1sıtma güçleri ile çalıştırılması ve böylece kombilerin yakıt tüketiminin ve bununla birlikte emisyonların azaltılması yönünde geliştirmelerin yapılabilmesi amacıyla bir deney sistemi oluşturulmuş ve ayrıntıları bu bölümde sunulmuştur. Deneysel çalışmada üç değişik model kombi cihazı kullanılmıştır. Bu cihazların mevcut deneysel çalışma ile ilgili teknik verileri Tablo 1.'de verilmiştir.

Görüldüğü gibi cihazlar benzer özelliklere sahip ve birbirine yakın 1sıl güç değerlerinde seçilmiştir. Kombilerin güç çıktılarının ve sıcaklık değerlerinin elde edildiği parametrik çalışmalar sonucunda elde edilen deneysel sonuçların karşılaştırılabilmesi için bu husus çok önemlidir. Cihazlardaki ana farklar isı eşanjörlerindedir. K1'de bileşik 1s1 eşanjörü, K2'de standart bileşik 1sı eşanjörü ve K3'de ise çift eşanjör uygulaması mevcuttur. Söz konusu cihazların daha ayrıntılı tanıtımı aşağıda verilmiştir.

Tablo 1. Deneysel incelemeleri gerçekleştirilen kombi cihazlarının teknik özellikleri (Technical properties of experimentally investigated combi-boilers)

\begin{tabular}{|c|c|c|c|}
\hline TEKNİK ÖZELLİKLER & K1 & K2 & K3 \\
\hline \multicolumn{4}{|c|}{ GENEL } \\
\hline Tip & Hermetik & Hermetik & Hermetik \\
\hline Ateşleme Şekli & Elektronik & Elektronik & Elektronik \\
\hline Yakıt & DG/LPG & DG/LPG & DG/LPG \\
\hline \multicolumn{4}{|c|}{ ISITMA DEVRESI } \\
\hline Isıl Güç $\left(80^{\circ} \mathrm{C}-60^{\circ} \mathrm{C}\right)(\mathrm{kcal} / \mathrm{h})(\max )$ & 20,400 & 20,640 & 20,600 \\
\hline Isıl Güç $\left(80^{\circ} \mathrm{C}-60^{\circ} \mathrm{C}\right)(\mathrm{kcal} / \mathrm{h})(\mathrm{min})$ & 8,300 & 6,192 & 6,200 \\
\hline Verim $(\%)$ & 92,2 & 93 & 93 \\
\hline Isıtma Devresi Sicaklık Ayarı & $30-85$ & $30-85$ & $30-85$ \\
\hline \multicolumn{4}{|c|}{ KULLANIM SUYU DEVRESİ } \\
\hline Kullanım Suyu Devresi Gücü (kcal/h) & 20,000 & 20,640 & 20,600 \\
\hline Kullanım Suyu Üretimi (lt/dk) $\left(\Delta \mathrm{t}=25^{\mathrm{O}} \mathrm{C}\right)$ & 13,6 & 13,7 & 13,7 \\
\hline Kull. Suyu Devr. Sic. Ayarı $\left({ }^{\circ} C\right)(\min -\max )$ & $40-60$ & $40-60$ & $40-60$ \\
\hline
\end{tabular}




\section{K1 Nolu Kombi}

K1 cihazı bileşik 1S1 eşanjörünü ihtiva etmektedir. Cihazın içten genel görünümü Şekil 1.'de verilmiştir. Şekil 2.'de söz konusu 1S1 eşanjörünün değişik açılardan görüntüsü sunulmuştur. Fotoğraflarda 1sitma devresi ile kullanım suyu giriş ve çıkış bağlantı boruları görülmektedir.

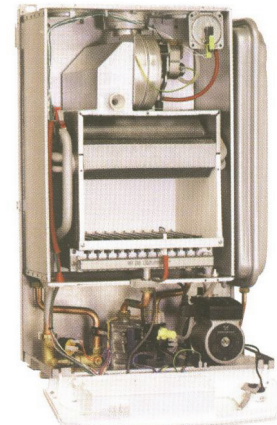

Şekil 1. K1 cihazının içten genel görünümü (General interior view of K1 combi-boiler)

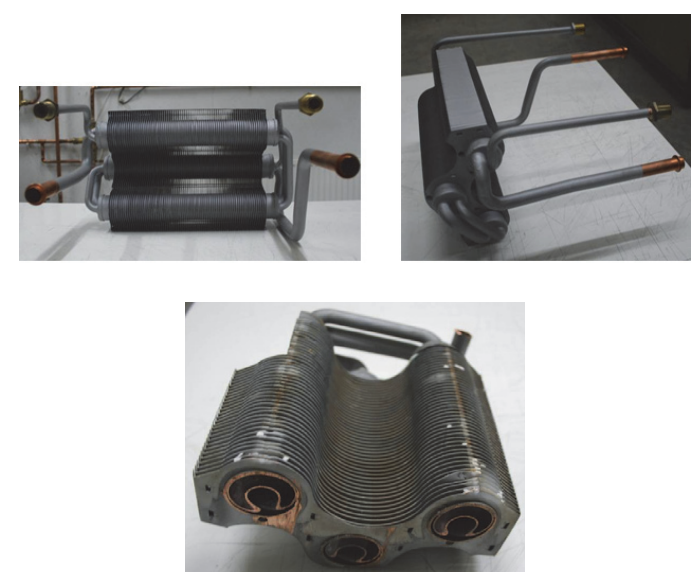

Şekil 2. K1 kombinin bileşik 1S1 eşanjörünün farklı açılardan görünümü (Different views of the combined heat exchanger of the K1 combi boiler)

\section{K2 Nolu Kombi}

K2 cihazı tipik düz bir bileşik 1sı eşanjörünü ihtiva etmektedir. Cihazın içten genel görünümü Şekil 3.’te verilmiştir.

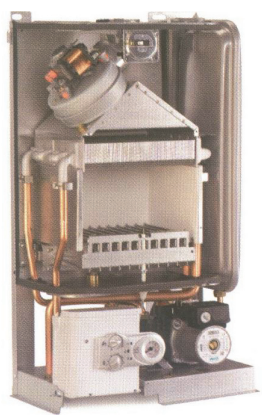

Şekil 3. K2 cihazının içten genel görünümü (General interior view of $\mathrm{K} 2$ combi-boiler)

\section{K3 Nolu Kombi}

K3 cihazı tipik bir çift ısı eşanjörlü kombi cihazıdır. Cihazın içten genel görünümü Şekil 4.'te verilmiştir.

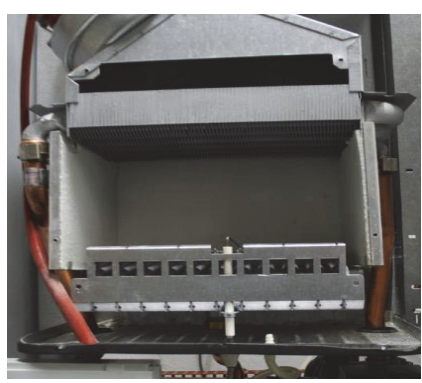

Sekil 4. K3 cihazının içten genel görünümü (General interior view of K3 combi-boiler)

Bu cihazda iki eşanjör bulunmaktadır. Şekil 5.(a)'da yanma odası yanma durumunda gösterilmiştir. Yanma odasının üst kısmında ana eşanjör görülmektedir. Şekil 5.(b)'de ise kullanım suyu üretiminde kullanılan plakalı eşanjör sunulmuştur.

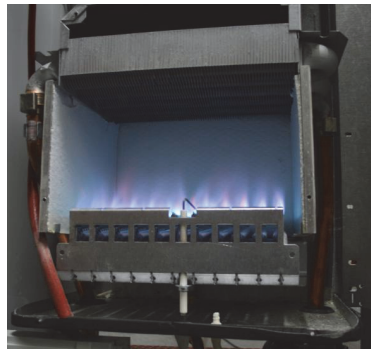

(a)

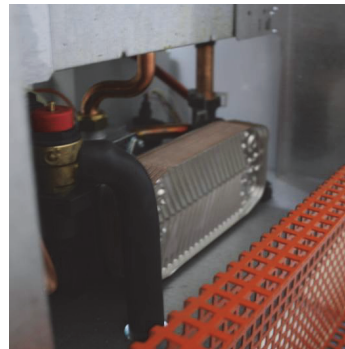

(b)
Şekil 5. K3 kombi cihazının yanma odasının ve plakalı kullanım suyu eşanjörünün görünümü (Combustion chamber and domestic water plate heat exchanger of K3 boiler)

Deney düzeneği, kullanılan ölçüm cihazları, deneysel metot ve verilerin değerlendirilmesinde, kaynaklarda verilen Türk Standartları kullanılmıştır [4-14].

Seçilen laboratuvarda 1sitma tertibatı bulunmamaktadır ve laboratuvarın büyük bir bölümü yerin altındadır. Ayrıca mekân olarak da oldukça büyük bir hacme sahiptir. $\mathrm{Bu}$ özellikleri ile laboratuvar ortam sıcaklıkları çok az değişmektedir. Ayrıca çoğunlukla $10^{\circ} \mathrm{C}$ sicaklığının altında bulunan laboratuvar kombi cihazlarının ürettiği ısının atılması için de çok uygundur. Deney düzeneğinin şematik ve genel görünümü Şekil 6.'da verilmiştir.

Deney düzeneğinin ana elemanları şunlardır: Kombi cihazı standı ve buna bağlı kombi cihazı, yakıt olarak kullanılan LPG tüpleri, sigortalı elektrik bağlantısı, kullanım suyu için lavabo, daldırma tipi sıcaklık probları ve veri toplama cihazı, debi ölçüm cihazları (rotametreler), tesisat bağlantı noktası, 1sıtma devresi radyatör grubu ve baca bağlantısı. 


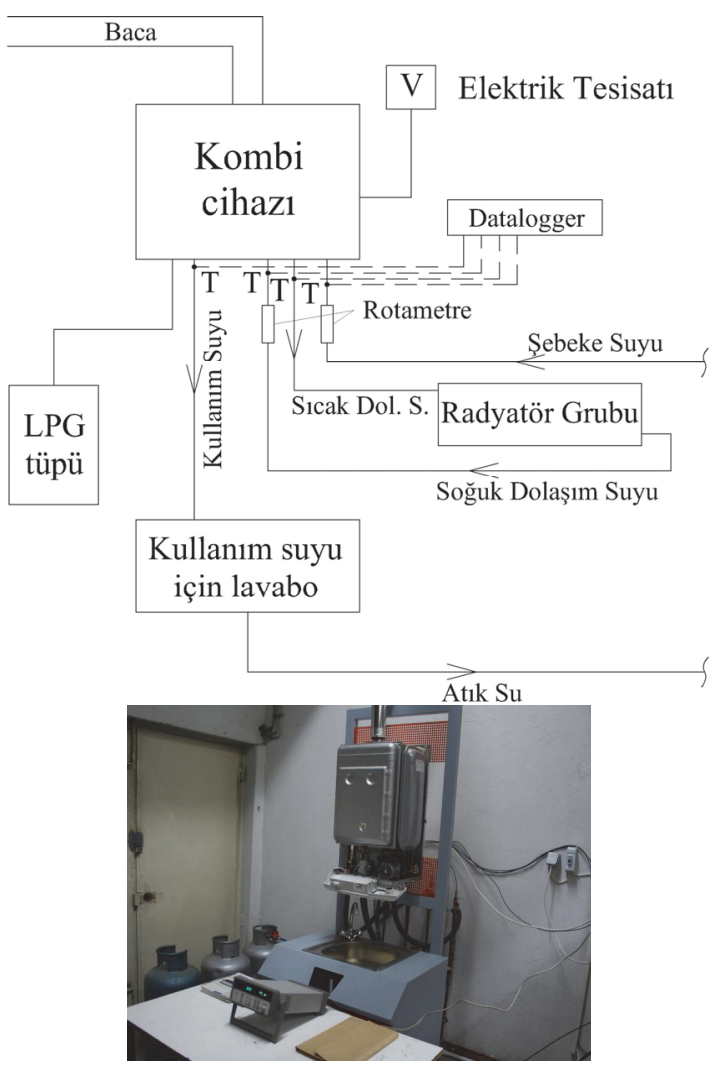

Şekil 6. Deney düzeneğinin şematik ve genel görünümü (Schematic and general view of experimental setup)

Şekil 7.'de sıcaklık ölçümlerinin alındığı, değerlendirildiği ve depolandığı Agilent marka 34970A model veri toplama cihazı (datalogger) ve dönüşümlü olarak kullanılan 52 lt (24 kg) kapasiteli LPG tüpleri görülmektedir.
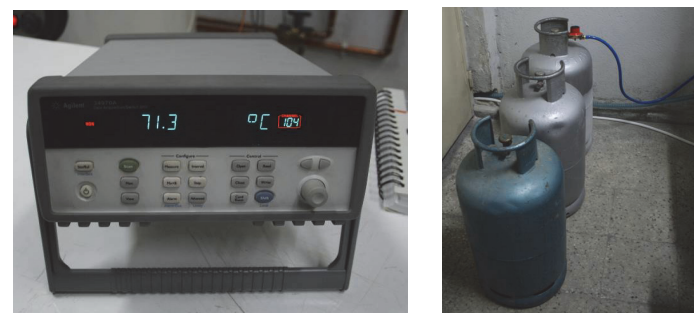

Şekil 7. Datalogger ile LPG tüpleri (Datalogger and LPG tanks)

Şekil 8.'de sol tarafta tesisat bağlantı noktasının genel görünümü ve sağ tarafta iki adet debimetrenin (rotametre) yakından görünümü verilmiştir. Kombipetekler-lavabo-soğuk su giriş-atık su olarak sıralayabileceğimiz ana hidrolik noktalar arasındaki tüm bağlantılar bu kısımda gerçekleştirilmiştir. Isıtma devresi ile kullanım suyu debilerini ayrı ayrı tespit etmek amacıyla iki adet $120^{\circ} \mathrm{C}$ sıcaklığa dayanıklı 220lt/dak ile 4-15lt/dak aralıklarında ölçüm yapabilen rotametreler kombiye en yakın konumlara yerleştirilmiştir.

Şekil 9.'da sıcaklık problarının yakından görünümü ve kombi baca bağlantısı gösterilmiştir. Sıcaklık ölçümlerinde J-tipi ısıl çiftler kullanılmıştır. Bunlar 80 mm boyunda, 1,5 mm çapında, 1/4" rekorlu daldırma tipi sıcaklık problarıdır. Sicaklık probları TS 4041'de verilen yerleştirme örneğine uygun olarak konumlandırılmıştır.
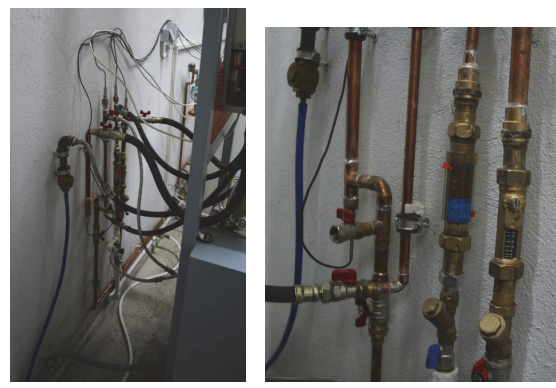

Şekil 8. Tesisat bağlantı noktasının genel görünümü ve iki adet debimetrenin (rotametre) yakından görünümü (General view of the installment and closer view of the two rotameters)
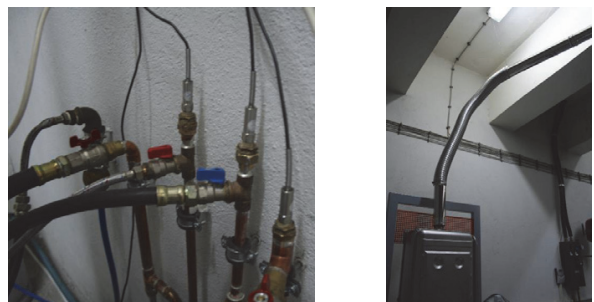

Şekil 9. Sicaklık problarının yakından görünümü ve kombi baca bağlantısı (Close view of the temperature probes and chimney connection)

Kombilerde üretilen 1sitma devresi 1sısının ortama atılması için iki adet $3 \mathrm{~m}$ boyunda $400 \mathrm{~mm}$ 'lik ve bir adet $1,2 \mathrm{~m}$ boyunda $600 \mathrm{~mm}$ 'lik PKKP tipi radyatörler kullanılmıştır. Radyatörlerin yerleşimi Şekil 10.'da gösterilmiştir.

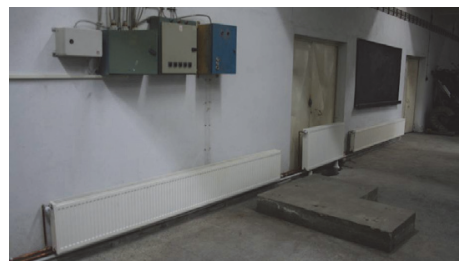

Şekil 10. Isıtma devresi petek grubu (Radiator group of heating cycle)

\section{DENEYSEL BULGULAR (EXPERIMENTAL RESULTS)}

$\mathrm{Bu}$ bölümde parametrik deneysel çalışma sonucunda elde edilen sonuçlar sunulmuştur. Gerçekleştirilen deneysel çalışmada kombi cihazlarındaki farklı eşanjörler kullanılarak kullanım suyu ve dolaşım suyu sıcaklıklarına ve ayrıca 1sıtma gücüne etkisi elde edilmeye çalışılmış ve böylece yüksek 1sıtma gücünün elde edildiği eşanjör tespit edilmeye çalışılmıştır. Bu kapsamda her üç kombi cihazı farklı çalışma şartlarında çalıştırılarak parametrik bir deneysel çalışma gerçekleştirilmiştir. Aynı zamanda K1 bileşik kombi cihazının üstünlükleri de tespit edilmeye çalışılmıştır. Her bir kombi için tüm deneyler, aynı 
soğuk laboratuvar şartlarında başlatılmıştır. Her bir deney ve aynı zamanda her bir kombi için, bütün deney şartları başlangıçta ve deney sonunda sabit tutulmuştur. Zamandan bağımsız şartların elde edildiği sürelerde deneyler devam ettirilmiştir.

Deneyler esnasında şu büyüklükler kaydedilmiştir: Ortam sıcaklığ $1,\left({ }^{\circ} \mathrm{C}\right)$; zaman, (sn, dk); 1sıtma devresi dönüş sıcaklığg1, $\mathrm{T}_{1 \mathrm{dd}} \quad\left({ }^{\circ} \mathrm{C}\right)$; 1 sitma devresi giriş sıcaklığı, $\mathrm{T}_{1 \mathrm{dg}}\left({ }^{\circ} \mathrm{C}\right)$; kullanım suyu giriş sıcaklığ $1, \mathrm{~T}_{\mathrm{ksg}}$ $\left({ }^{\circ} \mathrm{C}\right)$; kullanım suyu çıkış sicaklığı, $\mathrm{T}_{\mathrm{ksç}}\left({ }^{\circ} \mathrm{C}\right)$; pompa güç konumu, 1-2-3; rotametre debi değeri, (lt/dk); kombi cihazı çalışma özellikleri.

Yukarıda sıralanan ölçüm değerleri kullanılarak iş akışkanı debileri ve 1sıtma güçleri hesaplanmıştır. Kombi 1sıtma güçleri aşağıda verilen formüller yardımıyla hesaplanmıştır. Isıtma devresi için aşağıdaki formül kullanılmıştır.

$Q=\dot{m}_{l d} c_{p}\left(T_{\imath d g}-T_{\imath d d}\right)$

Burada $\dot{m}_{l d}$ 1sitma devresinde dolaşan suyun kütlesel debisini $c_{p}$ ise ortalama sabit basınçtaki suyun özgül ısısını göstermektedir. Kullanım suyu devresi için aşağıdaki formül kullanılmıştır.

$Q=\dot{m}_{k s} c_{p}\left(T_{k s \varsigma}-T_{k s g}\right)$

Burada $\dot{m}_{k s}$ kullanım suyu devresinde dolaşan suyun kütlesel debisini göstermektedir. Yukarıdaki hesaplamalarda suyun fiziksel özellikleri bulunurken ortalama sıcaklıklar kullanılmıştır.

Çalışma kapsamında, üç farklı kombi modeli ile, 1sitma devresi rejime gelme, isitma devresi rejimdeyken "ECO ON" ve "ECO OFF" konumlarında kullanım devresi rejime gelme, değişik debilerde kullanım suyu performansı, kullanım suyu rejimdeyken 1sıtma devresi rejime geçiş ve isıtma devresi rejimdeyken pompa konumu etkisinin incelenmesine yönelik deneyler yapılmıştır.

\subsection{Isitma Devresi Rejime Gelme (Time Dependent Change of Heating Cycle)}

Şekil 11.'deki iki grafikte de görüldüğü gibi üç kombinin ısıtma devresinin kararlı hale geliş zamanları ve elde edilen ısıtma devresi gidiş sıcaklık değerleri ve sıcaklık farkları birbirine çok yakındır. Fakat en yüksek 1sıtma devresi gidiş sıcaklığına ve sıcaklık farkına K1 kombisiyle ulaşılmıştır.

Şekil 12.'de 1sıtma gücünün zamanla değişiminden görüldüğü gibi kararlı hale gelme zamanları tüm kombiler için hemen hemen aynıdır. Kararlı hal ısıtma gücü değerlerinde ise $\mathrm{K} 1$ 'in 1sitma gücünün diğerlerinden bir miktar fazla olduğu görülmektedir.
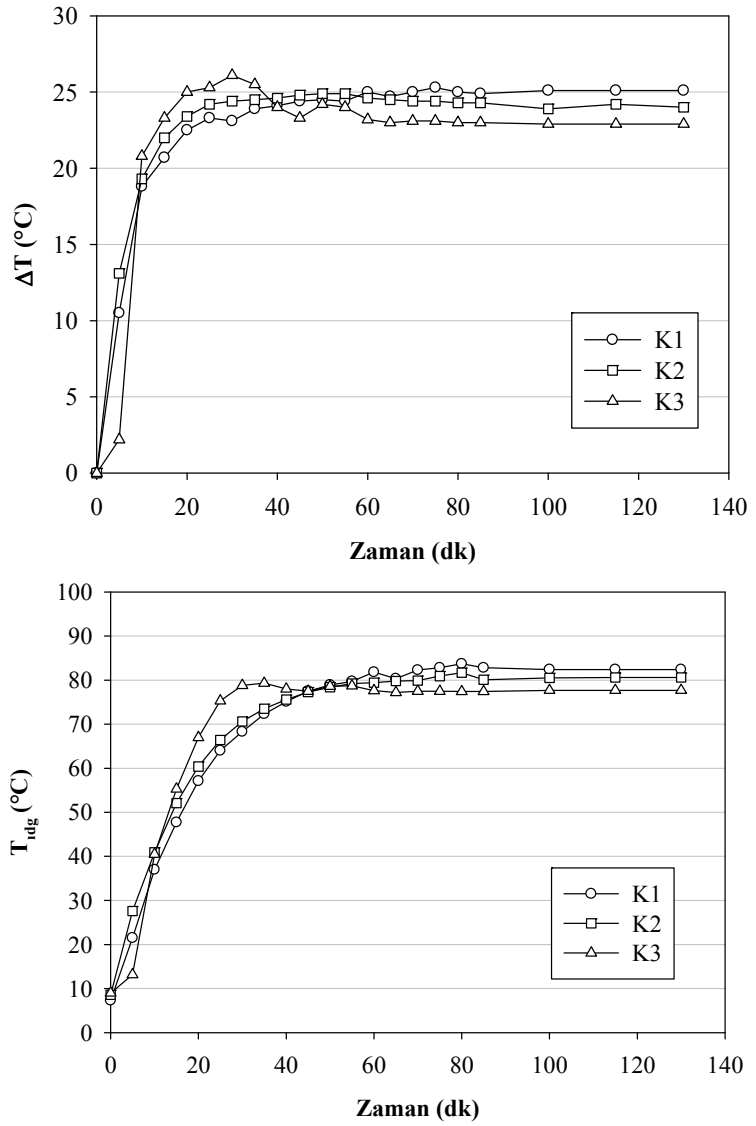

Şekil 11. Isıtma devresi sıcaklık farkının ve gidiş sıcaklıklarının zamanla değişimi (Time dependent change of temperature difference and outlet temperature of heating cycle)

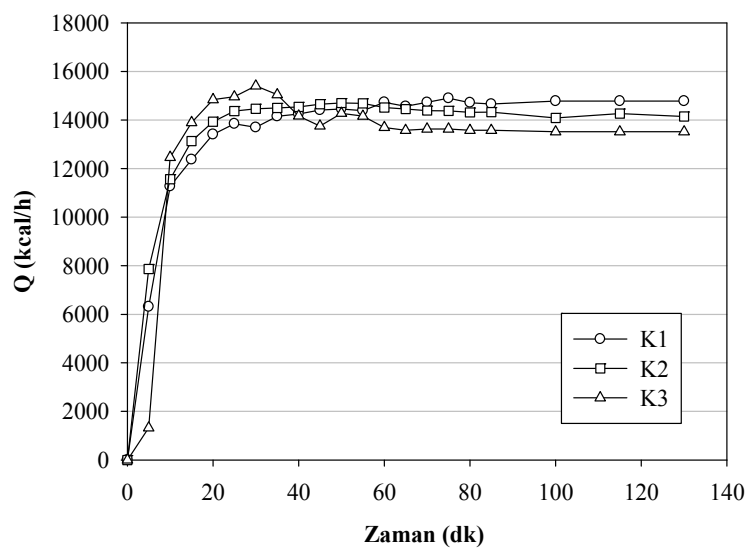

Şekil 12. Isıtma devresi 1sıtma gücünün zamanla değişimi (Time dependent change of heating cycle heating power)

3.2. Isıtma Devresi Rejimde Kullanım Suyu Rejime Gelme "ECO OFF" (Domestic Water Working Regime with Operating Heating Cycle "ECO OFF")

Şekil 13. ve Şekil 14.'te "ECO OFF" konumunda kullanım suyu çıkış sıcaklığı, sıcaklık farkı ve ısıtma gücü değerlerinin zamanla değişimi sunulmuştur. Görüleceği üzere K1 modeli diğerlerine kıyasla her üç büyüklük içinde daha yüksek değerlere sahiptir. K1 cihazı daha yüksek sicaklıkta kullanım suyu üretebilmektedir. 

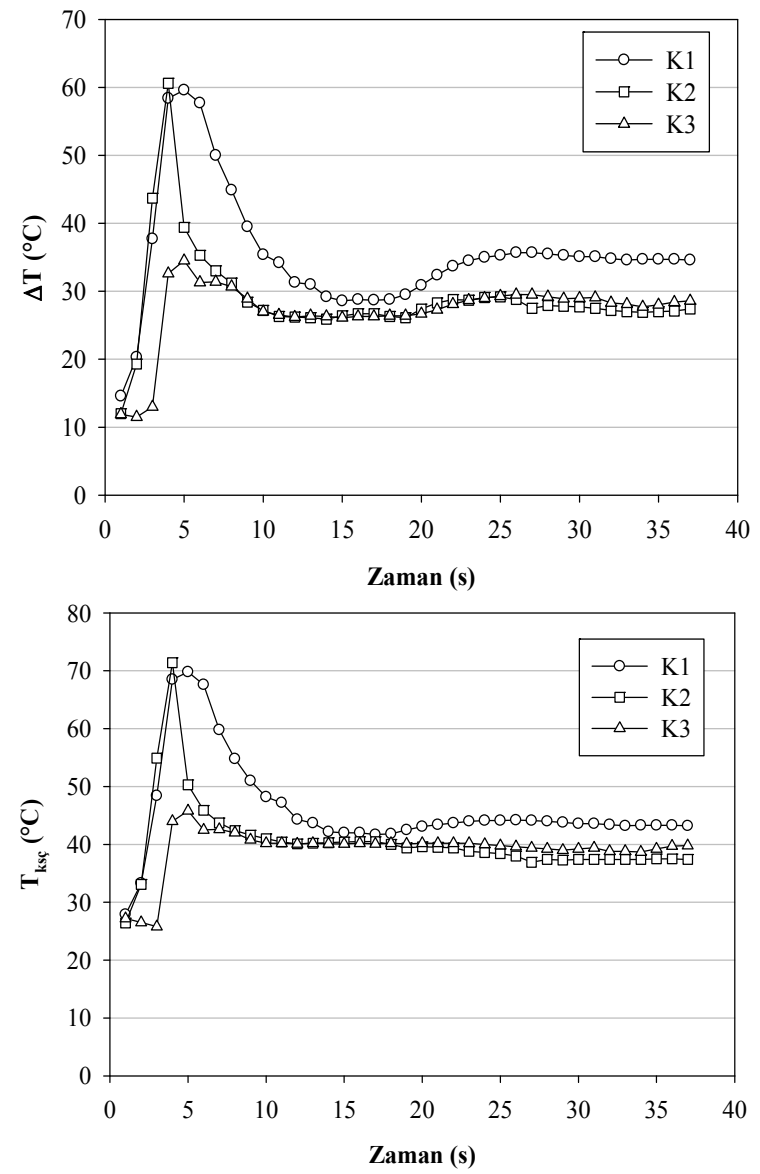

Şekil 13. Kullanım suyu sıcaklık farkının ve çıkış sıcaklığının zamanla değişimi (Time dependent change of temperature difference and outlet temperature of domestic water)

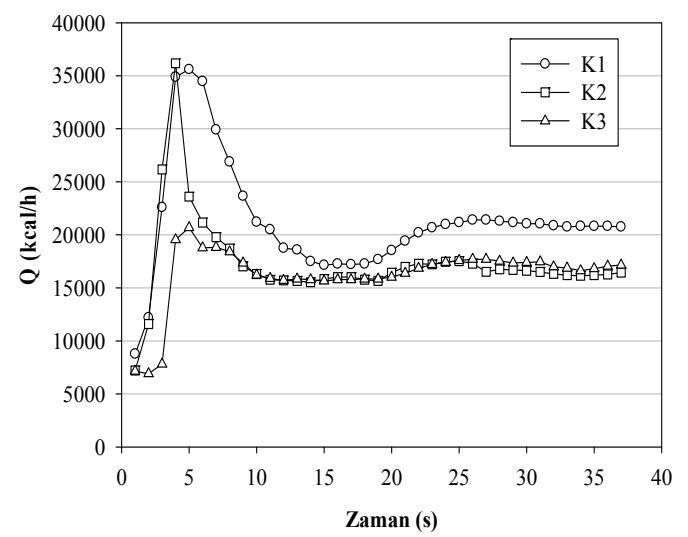

Şekil 14. Kullanım suyu devresi 1sıtma gücünün zamanla değişimi (Time dependent change of heating power)

\subsection{Isıtma Devresi Rejimde Kullanım Suyu} Rejime Gelme "ECO ON" (Domestic Water Working Regime with Operating Heating Cycle "ECO ON")

Şekil 15. ve Şekil 16.'da görüldüğü üzere "ECO ON" konumu için verilen, kullanım suyu çıkış sıcaklığı, sıcaklık farkı ve 1sıtma gücü değerlerinde K3 modeli az da olsa diğerlerinden daha yüksek sıcaklık, sıcaklık farkı ve 1sıtma gücü değerlerinde kararlı hale gelmektedir.
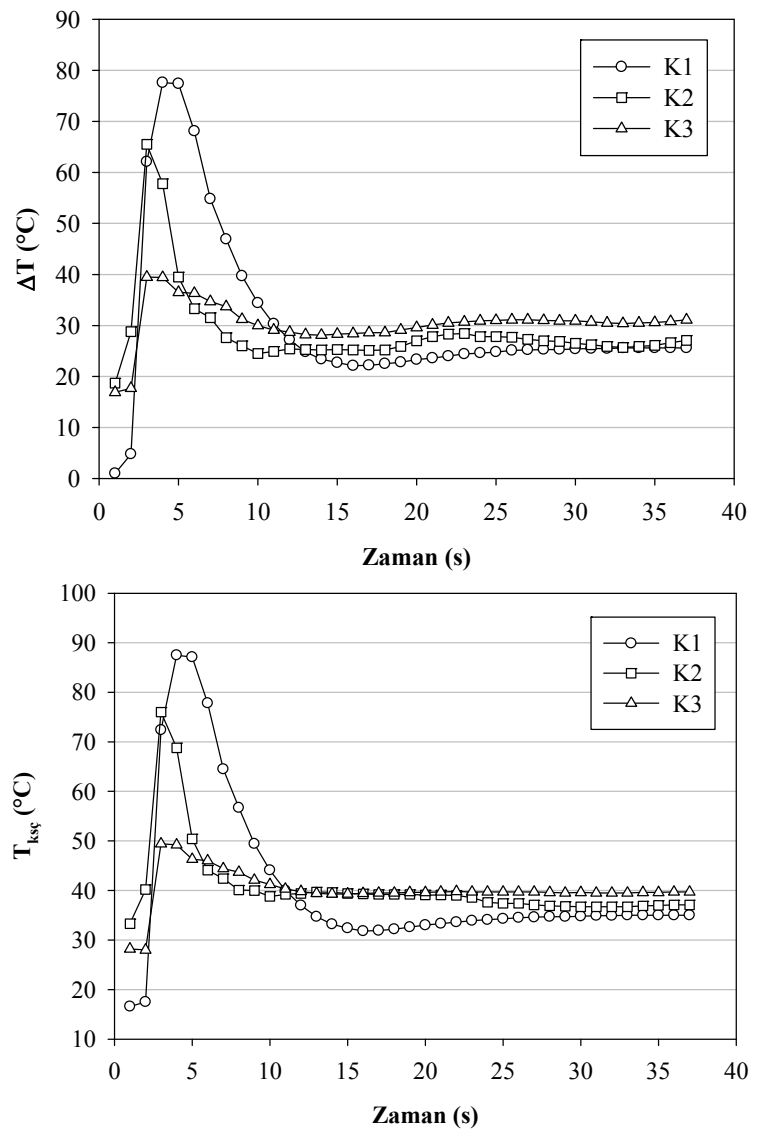

Şekil 15. Kullanım suyu sıcaklık farkının ve çıkış sıcaklığının zamanla değişimi (Time dependent change of temperature difference and outlet temperature of domestic water)

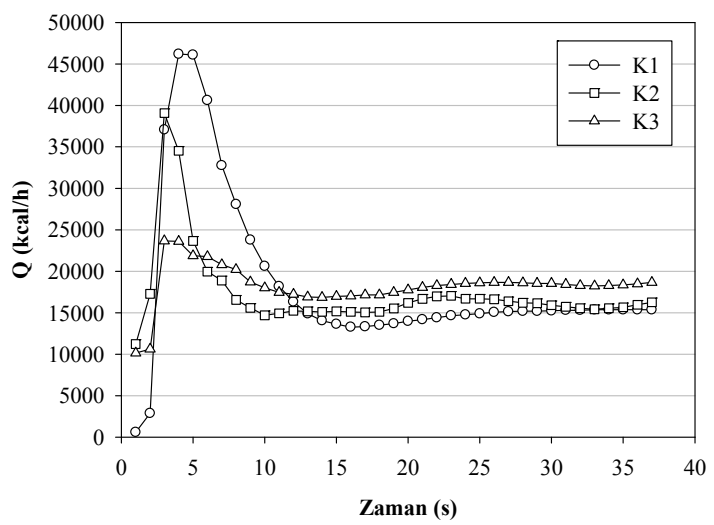

Şekil 16. Kullanım suyu devresi 1sıtma gücünün zamanla değișimi (Time dependent change of domestic water power)

3.4. Değişik Debilerde Kullanım Suyu Performansı (Domestic Water Performance for Different Mass Flow Rates)

Şekil 17.'de görülen kullanım suyu sıcaklık farklarına bakıldığında en yüksek debide K1 modeli, en yüksek sıcaklık farkı değerini verirken daha düşük debilerde, K3 modeli en yüksek sıcaklık farkı değerlerini vermektedir. Sicaklık farkı için yukarıda bahsedilen durum 1sıtma gücü için de geçerlidir. En yüksek debide K1 modelinin 1sıtma gücü diğerlerinden daha yüksektir. 

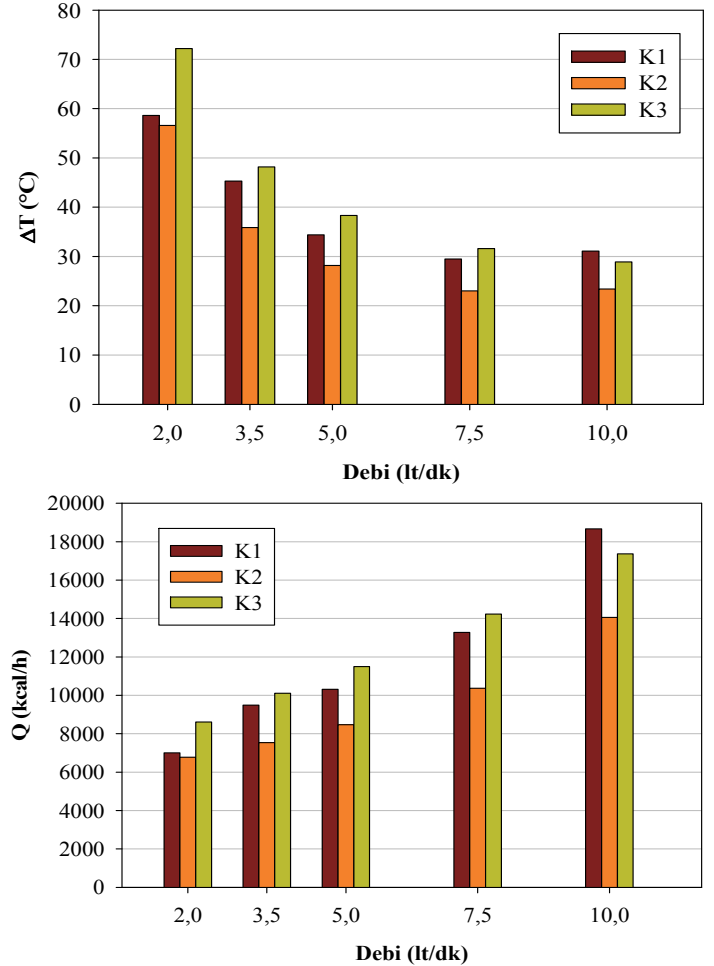

Şekil 17. Kullanım suyu sıcaklık farklarının ve ısıtma gücünün farklı debilerle değişimi (Variation of domestic water temperature difference and heating power with mass flow rate)

3.5. Kullanım Suyu Rejimde Isıtma Devresi Rejime Geçiş (Working Regime of Heating Cycle with Operating Domestic Water)

Kullanım suyundan ısıtma devresi rejimine geçişi gösteren Şekil 18.'de her üç kombi için hemen hemen aynı sıcaklık farkı değerleri aynı sürelerde elde edilmekte ve kararlı hale gelmektedir. Aynı biçimde Şekil 19.'da her üç kombi için aynı zaman içerisinde hemen hemen aynı ısıtma devresi gidiş sıcaklık değerleri elde edilmektedir. Isıtma güçleri de kullanım suyundan isıtma devresine geçişte bütün modeller için benzer zaman ve değerlerde sabitlenmektedir (Şekil 20).

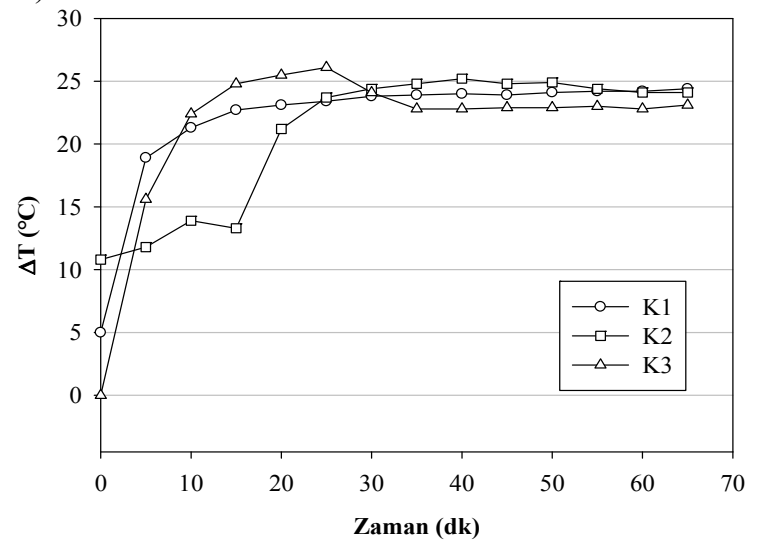

Şekil 18. Kullanım suyu rejimde, 1sitma devresi rejime gelirken sıcaklık farkının zamanla değişimi (Time dependent temperature difference of heating cycle with domestic water in use)

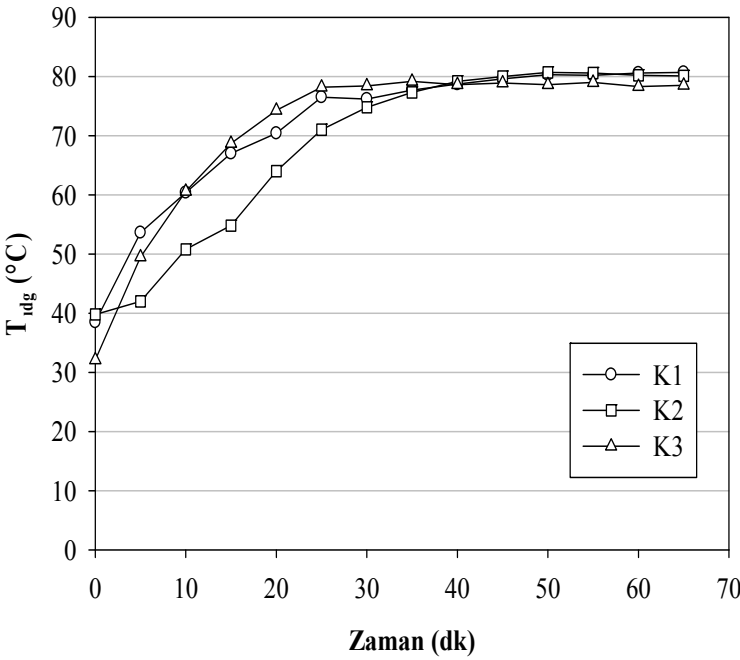

Şekil 19. Kullanım suyundan 1sitma devresini rejime gelirken, ısıtma devresi gidiş sıcaklığının zamanla değişimi (Time dependent water temperature of heating cycle with domestic water in use)

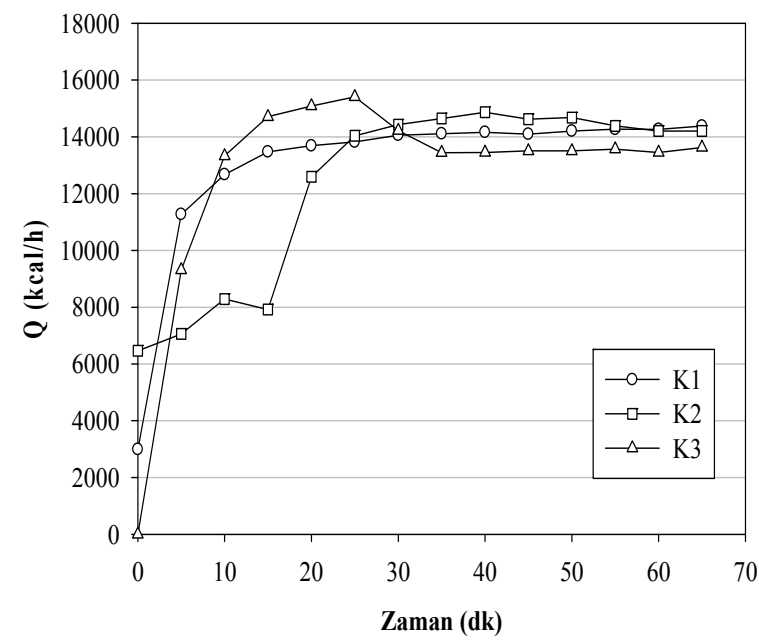

Şekil 20. Kullanım suyu rejimde, isıtma devresi rejime gelirken, ısıtma devresi gücünün zamanla değişimi (Time dependent change of power of heating cycle with domestic water in use)

\subsection{Isıtma Devresi Rejimde Pompa Konumu Etkisi (Effect of Pump Location on Heating Cycle)}

Şekil 21.'de görüldüğü üzere farklı debilerdeki ısıtma devresi durumu için sıcaklık farklarının fazla değişmediği görülmektedir. Her debi kendi içinde değerlendirildiğinde K1 modeliyle elde edilen sıcaklık farkı değerlerinin az da olsa diğerlerinden yüksek olduğu görülmektedir.

Şekil 22.'de 1sıtma devresi 1sıtma gücünün farklı debilerle değişimi gösterilmiş ve sıcaklık farkları için bahsedilen durumun benzeri burada da görülmüştür. K1 modelinin 1sitma gücü diğerlerinden az da olsa daha yüksek olduğu tespit edilmiştir. 


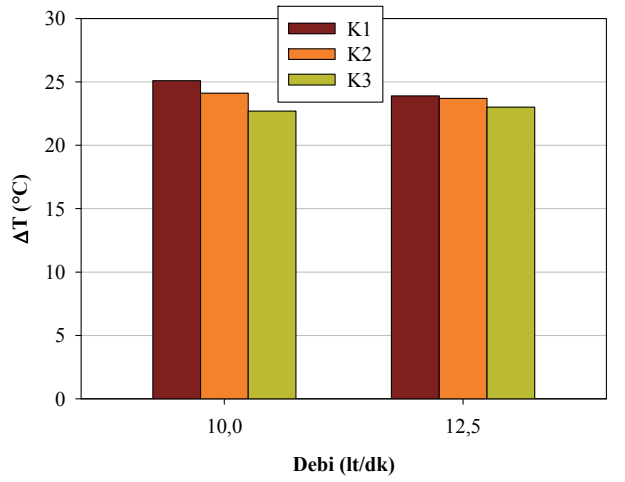

Şekil 21. Isıtma devresi sıcaklık farkının farklı debilerle değişimi (Variation of temperature of heating cycle with mass flow rate)

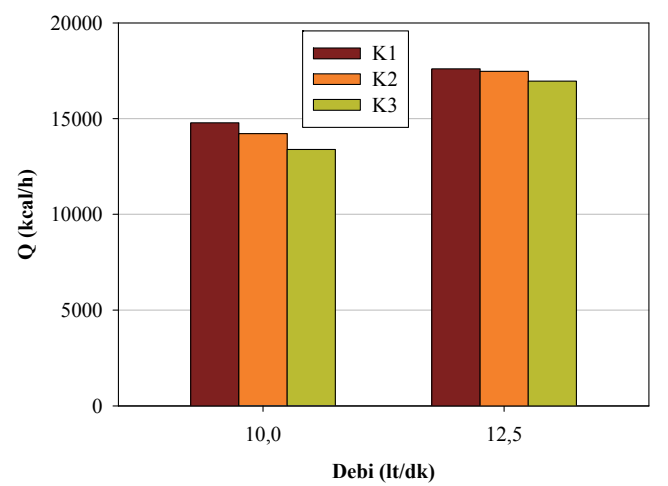

Şekil 22. Isıtma devresi 1sıtma gücünün farklı debilerle değişimi (Variation of heating cycle power with mass flow rate)

\section{SONUÇ (CONCLUSION)}

Mevcut çalışmada aynı şirkete ait üç farklı model kombi cihazının özellikleri deneysel olarak incelenmiştir.

Deneysel program kombi cihazlarının 1S1 eşanjörlerinin davranışlarını tespit etme hedefi doğrultusunda planlanmıştır. Aynı zamanda tüm 1sı hücrelerinin performansının belirlenerek K1 1S1 hücresinin üstünlükleri ve avantajları tespiti amaçlanmıştır. Test edilen kombilerin teknik özellikleri birbirlerine çok yakın ve performans değerleri açısından hepsi yaklaşık aynı güçtedirler. Cihazlar arasındaki en önemli fark 1S1 eşanjörlerindedir. Test edilen kombi cihazları ve kullandıkları 1s1 eşanjörü K1, K2 ve K3 olarak isimlendirilmiştir. K1 iç içe geçmiş üç adet serpantinden ve yüzeyi artırılmış kanatçıklardan oluşan bakır bileşik 1s1 eşanjörüdür. K2 iç içe geçmiş konvansiyonel bakır bileşik ısı eşanjörü ve son olarak K3 ana eşanjör ve kullanım suyu için plakalı eşanjörden oluşan çift isı eşanjörüdür.

Deneysel çalışma toplu bir biçimde değerlendirilerek maddeler halinde bulgular ve yorumlar aşağıda sunulmuştur.
- $\quad$ Soğuk ortam şartlarında kombi cihazı çalıştırılarak rejime gelme davranışı incelendiğinde kombilerin hepsinin yaklaşık aynı zamanda ve 40-60 $\mathrm{dk}$ arasında normal işletme şartlarına ulaştıkları tespit edilmiştir. Yalnız bu deneylerde K1 cihazının bileşik 1S1 eşanjörü ile $2-5^{\circ} \mathrm{C}$ daha yüksek sıcaklıklar ve buna bağlı olarak $1250 \mathrm{kcal} / \mathrm{h}$ civarında daha fazla 1 sıl güç elde edilmiștir.

- Isitma devresi rejimdeyken (ECO OFF) kullanım suyu sıcaklığının nasıl değiştiği incelenmiştir. $\mathrm{Bu}$ deneylerde bütün cihazlar yine benzer rejime gelme özellikleri göstermişlerdir. Bütün kombiler yaklaşık 10-15 s'de söz konusu debideki sürekli rejim şartlarına ulaşmışlardır. Yalnız yine bu deneylerde bileşik isı eşanjörü ile $6-7^{\circ} \mathrm{C}$ daha yüksek sıcaklıklar ve buna bağlı olarak $4310 \mathrm{kcal} / \mathrm{h}$ civarında daha fazla ısıl güç elde edilmiştir. Burada göze çarpan, bileşik ısı eşanjörlü kombilerde sıcaklıkların çok daha yüksek değerlerde olmasıdır. Bunun sebebi ise kullanım suyunun rejimde ve yüksek sicaklıkta bulunan 1sıtma devresi suyu ile aynı eşanjörde bulunmasıdır.

- $\quad$ Isitma devresi rejimdeyken (ECO ON) yine kullanım suyu sıcaklığının nasıl değiştiği incelenmiştir. $\mathrm{Bu}$ deneylerde bütün cihazlar yine benzer rejime gelme özellikleri göstermişlerdir. Bütün kombiler yaklaşık 10-15 s'de söz konusu debideki sürekli rejim şartlarına ulaşmışlardır. Yalnız bu deneylerde bileşik 1sı eşanjörü ile $2-5^{\circ} \mathrm{C}$ daha düşük sıcaklıklar ve buna bağlı olarak $3300 \mathrm{kcal} / \mathrm{h}$ civarında daha az 1sıl güç elde edilmiştir. Kombiler "ECO ON" konumunda çalıştırıldıklarında belirli bir sıcaklıkta hazır kullanım suyu tutmazlar ve buna bağlı olarak söz konusu miktarda sıcak suyu bulundurmak için gerekli ısı miktarı tasarruf edilmiş olur.

- $\quad$ Kombilerin farklı miktarlarda kullanım suyu üretim performanslarını incelemek için su debisi beş değişik değerde sabit tutularak deneyler yapılmıştır. Üretilen kullanım suyunun sicaklığı giriş sıcaklığına bağlı olduğundan elde edilen sıcaklık farkları karşılaştırılmıştır. Kullanım suyu debisi arttıkça doğal olarak elde edilen sıcaklık farkı düşmektedir. Düşük debilerde çift eşanjörlü kombi daha yüksek sıcaklık farkları oluştururken, yüksek debilerde bileşik 1sı eşanjörü daha yüksek performans göstermektedir. En yüksek debide $\mathrm{K} 1$ model cihaz $1-2{ }^{\circ} \mathrm{C}$, ve yaklaşık $4600 \mathrm{kcal} / \mathrm{h}$ daha üstün görünmektedir.

- $\quad$ Elde edilen sonuçlara bakıldığında kombilerin hepsinin yaklaşık 30 dakikada rejime ulaştığı görülmektedir. Farklı cihazların rejimdeki özellikleri ise çok az fark göstermektedir.

- $\quad$ Bütün kombiler üç kademeli sirkülasyon pompaları ile donatılmıştır. Yalnız cihazlarda iki değişik tip sirkülasyon pompası kullanıldığından bütün kademelerdeki debi değerleri aynı değildir. 
Yukarıda verilen bütün karşılaştırmalar tüm cihazlarda $10 \mathrm{lt} / \mathrm{dk}$ isitma suyu debisi verecek pompa konumları seçilerek yapılmıştır.

- $\quad$ Sonuçlara bakıldığında debinin değişmesiyle sıcaklıkların çok az değiştiği görülmektedir. $\mathrm{Bu}$ ise debinin artmasına rağmen cihazların daha fazla enerjiyi iş akışkanına aktararak aynı gerekli sıcaklık farklarını koruyabildiklerini göstermektedir. Bütün debilerde bileşik ısı eşanjörü daha yüksek sıcaklık (1$4{ }^{\circ} \mathrm{C}$ ) ve daha yüksek 1sıtma gücü (yaklaşık 1350 $\mathrm{kcal} / \mathrm{h}$ ) sağlamıştır.

Sonuç olarak, bileşik 1sı eşanjörlü K1 kombi cihazının diğer bileşik 1sı eşanjörlü ve çift eşanjörlü kombi cihazlarından 1S1 enerjisi transfer özellikleri bakımından hiçbir olumsuz davranışı ve özelliği tespit edilmemiştir. Tam aksine, yukarıda ayrıntılı olarak açıklanmış olan bir takım avantajları ve üstünlükleri tespit edilmiştir.

\section{SEMBOLLER (NOMENCLATURE)}

$c_{p}$ : Ortalama sabit basınçta özgül 1sı [J/kg.K]

$\mathrm{m}$ : Kullanım suyu kütlesel debisi $[\mathrm{kg} / \mathrm{s}]$

Q : Isitma Gücü [W]

$\mathrm{T}$ : Sicaklık $\left[{ }^{\circ} \mathrm{C}\right]$

\section{Alt Simgeler (Subscripts)}

1d : Isitma devresi

1dd : Isıtma devresi dönüş

$\mathrm{dg}$ : Isıtma devresi gidiş

ks : Kullanım suyu

ksç : Kullanım suyu çıkış

ksg : Kullanım suyu giriş

\section{TEŞEKKÜR (ACKNOWLEDGEMENTS)}

$\mathrm{Bu}$ çalışmayı finanse eden ve kombileri sağlayan Ferroli Isitma ve Klima Sistemleri Ticaret ve Servis A.Ş. Ankara bölge müdürü A. Serhat Özcan'a teşekkür ederiz.

\section{KAYNAKLAR (REFERENCES)}

1. Kakaç, S. ve Liu, H., Heat Exchangers: Selection, Rating, and Thermal Design, CRC, New York, A.B.D., 2002.

2. Kays, W. M. ve London, E. L., Compact Heat Exchangers, Krieger Publishing C., 1998.

3. Shah, R. K. ve Sekuliç, D. P., Fundamentals of Heat Exchanger Design, Wiley \& Sons, A.B.D., 2002.

4. TS EN 625, Gaz Yakan Merkezi Isıtma Kazanlar1-Anma Isitma Kazanlar1-Anma Is1 Yükü 70 kW'1 Aşmayan Kombine Kazanlar (Birleşik Isıtma Cihazları "Kombi") Sıcak Kullanım Suyu Üretimi İçin Belirli Şartlar, TSE, 1995.

5. TS 12514, Birleşik Isıtma Cihazları "Kombi" Gaz Yakan, Atmosferik Brülörlü-Anma Isı Gücü 70 KW'1 Geçmeyen-Montaj Kuralları, TSE, 1998.

6. TS EN 677, Gaz Yakan Merkezi Isitma Kazanları-Anma Isı Yükü 70 kW'1 Aşmayan Yoğuşmalı Kazanlar İçin Belirli Şartlar, TSE, 1995.

7. TS 4040, Makina Hz. Grb. Kazanlar-Isı Tekniği ve Ekonomisi Açısından Aranacak Özellikler, TSE, 1983.

8. TS 4041, Makina Hz. Grb. Kazanlar-Anma Is1 Gücü ve Verim Deneyleri Esasları, TSE, 1988.

9. TS 3818, Mühendislik Hizmetleri Hz. Grb. Isıtma Sistemleri-Gazlı Merkezi Yakma Tesislerinin Tasarımı, Yerleştirilmesi ve Güvenlik Kuralları, TSE, 1994.

10. TS 2754, Mühendislik Hizmetleri Hz. Grb. Kalorifer Kazanları İşletme, Muayene, Bakım ve Tasarımı Kuralları, TSE, 1977.

11. TS 1996, Makina Hz. Grb. Eşanjörler Isıtma Tesisleri İçin, TSE, 1975.

12. TS 12355, Yetkili Servisler-Kat Kaloriferleri ve Kombiler İçin Kurallar, TSE, Ankara, 2003.

13. TS $12355 / \mathrm{T} 1$, Yetkili Servisler-Kat Kaloriferleri ve Kombiler İçin Kurallar Tadil 1, TSE, 2003.

14. TS 12806, Kombi ve Kat Kaloriferi Bakım ve Onarımcısı, TSE, 2002. 
